\title{
Bioethics as Methodological Case Resolution: Specification, Specified Principlism and Casuistry
}

\author{
Ana Smith Iltis \\ Rice University
}

\begin{abstract}
Bioethical decision-making depends on presuppositions about the function and goal of bioethics. The authors in this issue of The Journal of Medicine and Philosophy share the assumption that bioethics is about resolving cases, not about moral theory, and that the best method of bioethical decision-making is that which produces useful answers. Because we have no universally agreed upon background moral theory which can serve as the basis for bioethical decision-making, they try to move bioethics away from theory. For them, a good method of bioethical decision-making is one which resolves cases in ways that are justifiable to the parties involved, not necessarily in ways that bring us "close" to the right and the true. The authors consider how the move away from theory and toward actual cases is best accomplished. In particular, the debate in this issue is about specification, specified principlism, and casuistry.
\end{abstract}

Key words: bioethics, casuistry, principlism, specification, specified principlism, theory

\section{BIOETHICS AS METHODOLOGICAL CASE RESOLUTION}

Contemporary bioethics emerged as fears about the progress of science grew along with the realization that no single traditional moral theory could be agreed upon to help resolve ethical questions. In his account of how bioethics developed, The Birth of Bioethics, Albert Jonsen writes that "the old tradition of medical ethics was too frail to meet the ethical challenges posed by the new science and medicine" (1998, p. 3). Historically, much of medical ethics was concerned with the social aspects of medical practice, namely describing the behavior of good physicians so that they might behave appropriately toward their patients (etiquette and bedside manner) and so that they might gain or maintain society's trust (social ethics) (Jonsen, 1998, pp. 6-7). Medical etiquette and the internal values

Correspondence: Ana Smith Iltis, Department of Philosophy, MS-14, Rice University, 6100 Main Street, Houston, TX 77005, U.S.A. Email: asmith@ ruf.rice.edu. 
of medicine proved inadequate for resolving new questions concerning abortion, organ transplants, brain death and so on. Even adherence to traditional injunctions, such as "do no harm," left many cases unresolved, especially those in which it was not clear what constituted harm. Medical ethical questions have also been addressed in the context of religious traditions over the centuries. For example, the Roman Catholic Church had identified a difference between the use of ordinary and extraordinary means to preserve life during the 16th century (Engelhardt, 1996, p. 284; Cronin, 1958). Even though religious traditions can and do give guidance on particular moral questions, the substantive moral theories they offer cannot help resolve cases in the public forum because their foundations are not universally recognized and agreed upon. For example, unless one already recognizes the teaching authority of the Roman Catholic Church, its instruction on a particular medical moral matter is not likely to influence one's choices. Neither traditional religious moral teachings nor medical etiquette and social ethics proved equal to the task, given the unavailability of traditional moral sources. How are we to proceed when faced with medical ethical issues in the context of actual cases requiring decisions? When hospitals, governments, and professional organizations want to develop policies regarding particular bioethical issues, how are they to proceed? How can we differentiate between right and wrong as we face issues of life and death?

The authors in this issue of The Journal of Medicine and Philosophy have been struggling with these questions for years, and here the debate continues. They all share the underlying assumption that bioethics is not about theory. Bioethics cannot be about theory because there is no universally agreed upon and recognized theory of right and wrong. So, the authors here concern themselves, in part, with delineating the appropriate ways in which the step away from theory, a step which bioethics seems to require in the face of moral theoretical diversity, ought to be taken. The essays in this issue are not about the "hot" topics of bioethics, e.g., they do not evaluate cloning, abortion, euthanasia, and so on. They are about how we should look at cases involving these and any other bioethical questions. The authors here have been in conversation with each other over the years. They do not pretend to offer final answers and resolutions. Rather, they here further the dialogue and offer the latest exposition of their agreements and disagreements.

Since they assume that bioethics is not really about theory, but about choices, decisions, and actions, what unifies the authors in this issue of The Journal of Medicine and Philosophy is their emphasis on the useful rather than on the right and the true. A distinction between the useful 
and the true was made by Henrik Wulff in Rational Diagnosis and Treatment:

physicians are primarily interested in whether classifications of diseases are useful, that is, whether they are efficient guides for physicians in reducing morbidity and mortality risk, not whether they accurately reflect reality (1981, p. 30).

Similarly, the authors in this issue all seek a method that will provide for justifiable case resolution, i.e., a useful method, rather than a method that will yield right or true answers as these might be theoretically established. ${ }^{1}$ Bioethics, for them, is about resolving cases in ways which can be justified to those involved but not in ways that are necessarily right. The goal and role of bioethics, for these authors, is practical decision-making, and so part of the test for a good bioethical method is that it is useful or practical in terms of the parties raising the bioethical questions. A reliance on moral theory would often make it impossible to justify decisions to the relevant parties because there is no universally agreed upon background moral theory. So, for these authors, bioethics requires that we step away from theory.

Principlism was one of the first contemporary attempts to ground a method of bioethical decision-making in something other than a moral theory (see Beauchamp and Childress, 1979). The idea was that, despite disagreement about moral and religious theories, we could all agree on certain principles. All we had to do was identify the 'common morality' and extract from it a set of middle level principles. This early attempt at developing a theory without a theory (i.e., a theory or method of resolving bioethical issues without relying on a foundational moral theory) could not deliver what it promised. Specified principlism developed as an attempt to respond to some of the criticisms of principlism, many of which revolved around problems associated with applying the principles to resolve cases. For example, how are we to deal with cases in which the principles conflict, and how are we to order the principles? Without a universally agreed upon background theory to tell us how to balance conflicting principles, we are unable to apply and use principles to solve ethical problems and answer moral questions. Trying to theorize without a theory is difficult, if not impossible.

In 1990, Henry Richardson examined what principlism needed in order to bring norms to bear on cases, i.e., to be useful. Noting the problems with the application of ethical theories, he began with a simple question: "Starting from an initial set of ethical norms [i.e., principles], how can we 
resolve concrete ethical problems?" (1990, p. 279). His principle claim in the 1990 paper is that we must specify our way to a solution, thereby "bring[ing] norms to bear on cases even while leaving them non-absolute..." He holds that "[o]nce our norms are adequately specified for a given context, it will be sufficiently obvious what ought to be done..." (1990, p. 294). In 1992, David DeGrazia wrote in support of Richardson's model of specifying principles and argued that specified principlism "is the most promising model" for bioethical theory (1992, p. 512). His goal at that time was, he said, "to ... unite principlism and specification explicitly and defend their union" (p. 533). The idea of specification would eventually change the way the early expositors of principlism, Tom Beauchamp and James Childress, understood their theory. In the fourth edition of The Principles of Biomedical Ethics, they noted that they accepted "Henry Richardson's argument that the specification of our principles is essential to determining what counts as an instance of that principle to overcome some moral conflicts" (1994, p. 29). Consequently, "in managing new, complex, or problematic cases, the first line of attack should be to specify your norms thereby to specify unclarities and problems away" (1994, p. 29). However, specification and specified principlism, like principlism as originally conceived, suffer from the problems associated with their nature - they are theories without theories. Without a universally agreed upon background theory to tell us how to specify principles and how to choose between conflicting specifications of a principle, we cannot proceed.

Just as the growing emphasis on dealing with actual cases, on the reality of moral pluralism, and on focusing on and attending to actual people and the particulars of a given case brought forth new ideas, such as specified principlism, the problems associated with those new ideas led to the revival of old ones, such as casuistry. Casuistry, i.e., the use of paradigm cases to determine how and when to apply moral rules to particular cases, can be traced back through the history of philosophy. It was used in religious thought and moral teachings as well as the legal system. In identifying the origins of casuistry, Albert Jonsen and Stephen Toulmin note that there is a long tradition of using case analysis in the Roman Catholic Church, which can be traced back to the early Christians and to Rabbinic Judaism (1988, p. 91). In these contexts of religion and law, casuistry was embedded in agreed upon theories about the world and who/what (e.g., priests, rabbis, councils, and the sanhedrin) had the authority to make decisions and judgments about which cases were paradigm cases and what the general moral rules were (Engelhardt, 1996, pp. 43 and 86). This is not the case for casuistry as used in contemporary bioethics. There is no univer- 
sally agreed upon background theory and no universal agreement about who is in authority. ${ }^{2}$ How are we to decide which cases are paradigm cases and which aspects of cases are morally relevant? The emphasis is on the usefulness of the method in producing an answer and yielding $a$ choice or decision. The emphasis is not on finding the (or $a$ ) right answer. The authors in this issue share this focus on methodology rather than theory, and on practicality (resolving cases in ways that can be justified by the relevant parties) rather than on truth (resolving cases in the right way).

\section{THE CURRENT DEBATE}

In the first part of this issue, Richardson presents critiques of Gert, Culver and Clouser's 1997 book, Bioethics: A Return to Fundamentals. Gert, Culver and Clouser respond, claiming that the central problem with Richardson's essay is that he has misunderstood them. In the second, Carson Strong critiques specified principlism and argues that it "fails the test of usefulness ... [because] ... it does not provide a practical method for arriving at justifiable resolutions of specific cases..." (2000, p. 324). Beauchamp responds to Strong's criticism, arguing that casuistic reasoning depends on specified principlism to compare, and therefore to resolve, cases. Jonsen also responds to Strong's paper, claiming that specified principlism and casuistry need each other "to get close to" actual cases.

\section{A. Method 1: Specification, Not Balancing}

Richardson argues in 'Specifying, balancing, and interpreting bioethical principles' (2000, pp. 285-307) that his decade-old work on the notion of specifying norms progressively has not been fully assimilated into the bioethics literature and that the language of specified principles should replace the language of balancing in bioethics. ${ }^{3}$ The importance of specifying principles or interpreting norms in some way has been recognized in some of the major bioethical theories, but Richardson argues that there is still a heavy and inappropriate reliance on balancing. In his essay here, Richardson attempts to expose the ways in which Gert, Culver and Clouser rely on 'global' or 'overall' balancing between a theory's principles despite their stated openness to specification or some kind of interpretation of norms. Furthermore, he critiques Beauchamp and Childress' reliance on balancing as a way to resolve conflicts between bioethical principles. Finally, Richardson argues that the only appropriate role for balancing is within the context of a particular principle (i.e., 'piecemeal' and 'contextual' balancing) and that specification ought to replace balancing. 
Richardson explains that his main "target is ... the use of the idea of balancing ethical principles..." by Gert, Culver and Clouser, and by Beauchamp and Childress, not their theories as wholes (2000, p. 287).

Richardson denies the appropriateness of the kind of balancing in which he claims Gert, Culver and Clouser engage ('global' or 'overall' balancing) because it violates or fails the test of the weak principle of publicity. The weak principle of publicity is one of Richardson's basic assumptions. He says, "[j]ustifications must be offered in terms of reasons that may be publicly stated" (2000, p. 286 ). Richardson argues that Gert, Culver and Clouser use 'global' balancing because for them morality is about minimizing harm, and violations of moral rules are justifiable when the harm that results from the violation is greater than the harm that results from not violating it (Richardson, 2000, p. 294). This method, according to Richardson, constitutes 'global' balancing, and it does not meet the weak publicity requirement because harms are incommensurable and hence one cannot (publicly) give real reasons for the violations or for allowing the violations. Richardson concludes that "by depending on intuitive quantitative balancings whose basis cannot be publicly expressed because there is no actual quantitative dimension backing them up and by failing to encourage the public articulation of the actual, qualitative basis of such judgments," Gert, Culver and Clouser's method of bringing norms to bear on actual cases does not meet the weak requirement of publicity and therefore it is not an appropriate method (Richardson, 2000, p. 297).

At the root of Richardson's dismissal of what he sees as Beauchamp and Childress' use of balancing to resolve conflicts among principles is his claim that specification is better than balancing for producing action-guiding principles. According to Richardson, the use of balancing to resolve conflicts among principles "go[es] against the requirements of the cooperative development of action-guiding theory" (Richardson, 2000, p. 298), which Richardson assumes is one of the functions of bioethics. ${ }^{4}$ His rejection of the balancing he identifies with Gert, Culver and Clouser, and with Beauchamp and Childress, is based on what Richardson takes to be the role, function or purpose of bioethics. Bioethics is, for him, about guiding actions, not about theory. It is about bringing norms to bear on cases in the "real" world, and thus requires cooperation between theoreticians and practitioners, not just theory: the superiority of specification "lies in the greater contribution of specifying and interpreting norms to the overall enterprise of progressively developing action-guiding principles. Contributing to this enterprise, I assumed at the outset, is part of the purpose of work in bioethics" (2000, p. 304). His criticism of Gert, Culver and Clouser and of Beauchamp and Childress seems to be that they lack the 
proper connection to the real or the concrete (i.e., to the public world of cases and policies), such that their approaches cannot guide actions as well as specification can. They do not bring principles, norms, or rules to bear on cases in the appropriate ways. Appropriateness, for Richardson, is determined by usefulness in the public sphere, and not by how "close" it is to the truth.

Gert, Culver and Clouser respond directly to Richardson's attack. Their first point is that Richardson's presentation and understanding of their work is "distorted." One central problem with Richardson's view of their work, they argue, is that Richardson writes as if they think there are special 'bioethical principles'. However, they specifically deny such principles, holding instead that bioethics uses the same morality as every other aspect of life - the common morality: "bioethics involves the same morality that applies to the rest of life and ... there are no unique principles of bioethics that are distinct from the common moral system" (2000, p. 309).

Central to their theory - a point they think Richardson misses - is Gert, Culver and Clouser's understanding of moral rules as being part of a whole system and not as free-standing or independent principles. It is because of this error, they think, that Richardson accuses them of using 'global' or 'overall' balancing. They claim that the rules are all part of an existing moral system, and that the task of bioethics is to make that moral system explicit:

We regard the rules as part of a complete moral system, comparable to the grammar of a language, which everyone who speaks the language knows, but which only grammarians make explicit. We view ourselves as trying to make common morality explicit. The moral rules are only one part of the common moral system, the other parts being the moral ideals, the morally relevant features, and the two-step procedure for determining when it is justified to violate a moral rule. We view it as misguided to try to resolve conflicts between moral rules by either specification or balancing, for we regard the moral rules as part of a system which includes a two-step procedure for determining when it is justified to violate a moral rule (2000, p. 311).

Bioethics is, for them, about bringing the common morality they think all rational persons share to bear on bioethical cases and determining if the answers the common morality yields are justifiable.

Gert, Culver and Clouser have a two-step procedure for describing an action which is a violation of one or more moral rules of common morality and determining if the violation is justifiable. The first step is to describe 
the morally relevant features of the violation; the second step is to estimate the harms that would result from publicly allowing versus not allowing the violation. This idea of estimating harms, they think, is the source of Richardson's accusation of balancing and hence of his claim that their method violates the weak principle of publicity. Even though Richardson may think that the second step involving the estimation of harm involves 'global' balancing, for Gert, Culver, and Clouser, estimation is about connecting ethical decision-making to the public world in which actual cases arise and must be resolved. For them, the estimation of harms is about meeting a strong publicity requirement. Their method requires that we estimate "the results of the violation being publicly allowed ... to determine whether one would publicly allow the violation" $(2000$, p. 312$)$. They find it "difficult to see how this use of 'global balancing' could possibly be in conflict with publicity, when it is based on one's estimates of the results of the violation being publicly allowed and is used in order to determine whether one would publicly allow the violation" (2000, p. 312).

At the heart of Gert, Culver and Clouser's method is a concern about how to justify the violation of moral rules, not how to interpret moral rules, as Richardson seems to think. Furthermore, they, unlike Richardson and most philosophers,

intend to describe the common moral system that thoughtful people use, generally unconsciously, when making moral decisions and judgments. We try to make that system explicit and then to see if it can be justified, that is, whether, with suitable qualifications, all rational persons would put forward this system as a public guide for everyone's behavior. This means that, contrary to the practice of most philosophers, we attempt to provide a full description of common morality. We do not attempt to generate answers from our moral theory, but rather to describe the answers that are given by common morality, and to determine whether these answers can be justified (2000, pp. 315-316).

Their goal is to "provide ways of describing a particular case via the morally relevant features, so that it becomes clear how the moral system applies to that case" (2000, p. 316). This is what will be useful, they claim, and Richardson cannot show how specification is similarly useful (2000, p. 316). Again, it is clear that Gert, Culver and Clouser's emphasis is on the practicality and usefulness of their method for resolving actual moral controversies. They are not interested in determining if the resolution measures up to some "higher standard" of the right and the true. They are interested in how best to resolve cases, where "best" is measured by how 
good a method is for helping us arrive at a decision that coheres with what they call the "common morality'. "Best" is not measured by how good a method is at helping us come to the right resolution.

Gert, Culver, and Clouser, and Beauchamp and Childress, try to develop useful methods of bioethical decision-making; they want methods that will facilitate the resolution of actual cases. Richardson argues that they all fail to fulfill their aim and that in order to succeed they would need to incorporate (further) specification into their methods. He is not critical of their goal, i.e., of developing methods that will resolve cases and produce answers instead of ones that will lead to the truth. Rather, Richardson is critical of their product.

\section{B. Method 2: Casuistry}

Casuists posit their method as an alternative to specified principlism and other approaches to bioethical decision-making. It is a method emphasizing full appreciation of cases. In 1988, Jonsen and Toulmin published The Abuse of Casuistry in an attempt to renew respect for casuistry as a method of moral reasoning. Since then, a variety of forms of casuistry have been presented in the literature. ${ }^{5}$ In this issue of The Journal of Medicine and Philosophy, Carson Strong defends a form of casuistry which recognizes the importance of ethical principles. He argues that some versions of principlism and casuistry are compatible, but that specified principlism is not a practical method of making ethical decisions and resolving cases. One of Strong's criticisms of Richardson's 1990 paper is that Richardson's examples do not include enough details. Strong tries to "fill in the blanks" and see what specification would offer when faced with an actual case (or at least with a more realistic sample case). Strong identifies two central problems with specification that become evident when one does look at a case with more details: first, the way one chooses to specify the principles depends on prior choices about assigning priorities to principles that conflict, and second, another method (such as casuistry), rather than specification itself, does the work of actually assigning priorities to the principles.

Strong tries to demonstrate the usefulness of casuistry (as he understands it) in determining which specification will enhance coherence among norms, as specified principlism requires. He tries to show that specified principlism needs another method to do the reasoning, and casuistry can be this method. Specified principlism needs a method that will allow one to "assign priorities to conflicting principles in clinical cases" (2000, p. 330). There is a sense in which casuistry might be a pre-requisite for specified principlism. 
Casuistry, Strong says clearly, is not an ethical theory, and casuists do not claim to offer an ethical theory, to be able to give absolute answers, or to be able to resolve all cases. Rather, casuistry is a "method of arriving at justifiable decisions ... [in] ... specific cases" (2000, p. 330), and "yield[ing] conclusions that are discursively justifiable," and this is precisely what Strong thinks is required of good methods of doing bioethics (2000, p. 330). Casuistry is about dealing with actual ethical cases and making it possible to come to justifiable resolutions in such cases; it is not about theory or about the search for the truth.

In Strong's description of bioethics, we see again the step away from theory. Casuistry seems to be, in part, a way to use theory, in the form of ethical values, to resolve cases. In Strong's five-point description of his own version of casuistic analysis, the emphasis clearly is on action and choice rather than on identifying what is right or true. The reasons Strong claims casuistry is superior to specified principlism revolve around his view that casuistry is more useful. He says, "the claim that specified principlism provides the most promising method for resolving concrete cases and issues in medical ethics is unwarranted. It does not constitute a useful decision procedure for resolving concrete cases, and the claim that it is preferable to casuistry for such a purpose is unfounded" (2000, p. 339). Strong's central concern is the resolution of cases, and this, he thinks, is the work of bioethics. It is work that specified principlism cannot do without casuistic reasoning (2000, p. 339).

Beauchamp's response to Strong's essay emphasizes that Strong's "criticisms are either off the mark of the principlism [Beauchamp] defend[s] or fail as criticisms of it" (2000, p. 342). His focus is tackling Strong's argument that specification does not give practical help in resolving cases and that casuistry is a better method (not theory) than principlism and specified principlism. In response to Strong's central criticism of Richardson's 1990 paper (i.e., that Richardson's example lacks details), Beauchamp says that those who espouse specified principlism are well aware that as different and harder cases emerge, further specification will be necessary. Such cases will require that we refine our commitments. Beauchamp responds to Strong's claim that casuistry does all the work of reasoning and justification, even when we use the language of specification, by arguing that just because specified principlism has not done all the work to be done does not mean that it (specified principlism) cannot do it. It is simply the case that there will be a need for greater specification (2000, p. 344).

Beauchamp then enumerates three points Strong identifies as differences between his brand of casuistry and Beauchamp and Childress' method, points which Strong uses to argue that casuistry is a better method than 
specified principlism. For all three, Beauchamp argues that he and Childress actually do what Strong says they ought to but do not do. He concludes that rather than specified principlism needing casuistry, as Strong claims, casuistry needs specified principles. In order to compare paradigm cases to the actual cases to be resolved, as casuists would, there must be a way to transfer the values between the paradigm and actual cases: "For a casuist to reason morally, one or more settled values must connect the cases (hence the necessity of 'maxims', or moral generalizations)" (Beauchamp, 2000, p. 346). The values are what actually connect the cases, and these values are what specified principlism is about for Beauchamp and Childress. Beauchamp concludes that he does not object to casuistic reasoning, but that casuistry needs specified principlism to transfer values between cases and therefore to be able to compare cases.

Casuists sometimes write as if cases lead to moral paradigms, analogies, or judgments entirely by their facts alone or perhaps by appeal only to the salient features of the case. But no matter how many salient facts are stacked up, we will still need some transferable value premises in order to reach a moral conclusion. The properties that we observe to be of moral importance in cases are picked out by the values that we have already accepted as being morally important. In short, the paradigm cases of the casuists are value-laden with general norms, and a case would not be a paradigm case without those normative commitments. To this extent, general principles do not follow from cases (even if it is also true that paradigm cases do not follow from principles) (Beauchamp, 2000, p. 346).

In Beauchamp's response to Strong's criticisms of specified principlism and in Beauchamp's description of what he and Childress try to do in developing their theory, it is clear that Beauchamp sees himself engaged in a project aimed at coping with medical-morality reality. That is, he and Childress want a method, not a theory, that can actually be useful in resolving cases. As different cases emerge, they inform us as to the areas where greater specification is required (2000, p. 344). Beauchamp and Childress, like Gert, Culver and Clouser, are trying to identify the common morality and bring it to bear on cases. Like casuistry, Beauchamp and Childress' specified principlism is a case-based approach, not a theorydriven one: it is from the "hard" cases that we learn of the need to specify principles further (2000, p. 344).

Jonsen begins his response to Strong's essay with a clear statement that he is concerned with practical ethics and resolving actual cases. He says that 
he and Toulmin wrote The Abuse of Casuistry (1988) with the intent to show that casuistry has a legitimate role in practical ethics. So they, like the other authors here, are interested in finding a way to move out of the realm of the theoretical and into the realm of actual cases requiring moral reasoning to be resolved. Jonsen compares a moral case to a painting, Velásquez's Las Meninas: ethical theory and the cultural ethos serve as the background to the case, the maxims and principles relevant to the case serve as the midground, and the circumstances and particular individuals involved in the case serve as the foreground. Moral philosophy is about filling in the background - the theory; casuistry, on the other hand, is about the middle and foregrounds. Casuistry is about determining which maxims and principles are relevant to a particular case, looking at cases and coming to justifiable resolutions. Jonsen's emphasis is on the relationship between the middle and foregrounds. He is critical of Richardson for being stuck in the middle ground and focusing only on principles and maxims, specified though they may be; and he is critical of Strong for focusing only on the foreground, on the individuals and the specifics of a given case. What is central to his and Toulmin's casuistry, Jonsen claims, is the constant conversation between the middle and foregrounds. And this, he claims, is why "specification and casuistic analysis need each other to get close to the case" (2000, p. 359). To move away from theory - to step out of the background - requires that we walk back and forth between the middle ground and the foreground, between the principles relevant to a case and the specifics of that case. So, Jonsen, like the other authors, is concerned and has been concerned for quite some time with how to engage in practical ethics - the appropriate and justifiable ways of making moral decisions - and not with formulating ethical theory. He concludes that the appropriate way is to allow the background of ethical theory to shed light on the maxims and principles relevant to a case and then look at the particulars of that case.

The essence of Strong's argument is that his casuistic method is the best one for resolving bioethical cases and Beauchamp's specified principlism requires a method such as casuistry to do the work of reasoning and justification. Beauchamp, on the other hand, argues that his method of specified principlism is the most useful for resolving cases and that Strong's casuistic method cannot resolve cases without specified principles. Jonsen's essay suggests that, in a sense, they are both right: specified principlism and casuistry need each other. Despite the various levels of agreement and disagreement between Strong, Beauchamp, and Jonsen, all three share the assumption that the function of bioethics is to resolve cases and that the best method of bioethical decision-making is that method which proves most useful in doing this. 


\section{CONCLUSION}

The essays and response essays in this issue of The Journal of Medicine and Philosophy investigate how to leave theory behind, given the absence of agreement on a background moral theory, and how instead to resolve ethical cases efficiently. At a deeper level, this discussion is about what bioethics is and what its goals and roles can be. Is bioethics supposed to be about discovering, determining, or identifying the right and the true? Or is it about coming up with solutions to cases in ways that can be justified to the players in those cases? In terms of policy, is the role of bioethical reflection to help determine what is right and true, or is it about coming up with policies that we can "get away with" or that can prevent legal problems? These essays are not about particular topics in bioethics; they are about bioethics per se. What is bioethics about? What are bioethicists out to do, and what is the best way to do it? All the authors in this issue share the assumption that bioethics is about making real choices and resolving actual cases. They disagree about the best way to regard and resolve those cases, but they agree that the answer does not rest in a moral theory and they agree that they are not after the truth. Their goal is to develop the most useful method of case-resolution, namely one that produces answers justifiable to a particular public. One is left with the question of precisely what constitutes a justifiable answer and why this is the standard for bioethical decision-making. What is clear is that justifiable does not mean true or right. In some sense, justifiability is a lower standard than is truth. Nevertheless, it may be the only standard available given the absence of a universally agreed upon background moral theory.*

\section{NOTES}

* I would like to thank Lisa Rasmussen for her help with this essay. She helped refine my understanding of these authors and commented on many drafts.

1. By "right" and "true" here I presuppose that rightness and truthfulness in moral matters are not determined simply by what we can agree upon or what we can justify to a certain group of individuals.

2 . For a discussion of the importance of who is in authority and the distinction between being in authority and being an authority, see Engelhardt, 1996, pp. 322-323, and Engelhardt, 2000.

3. B.A. Brody distinguishes between the language of balancing and weighing. He offers a concise and definitive argument against the use of the language of weighing while relying on a particular use of balancing language in Life and Death Decision Making (1988, pp. 76-77). His central claim is that conflicting moral appeals must be balanced (p. 75), and the question is how. He argues against various approaches, including what he calls the 'Scale Approach'. The Scale Approach requires that we construct 
"a common scale so that we can add the strengths of the various appeals on each side ..." (p. 77). Such a common metric seems unfeasible (p. 77), and without a common metric we cannot weigh different moral appeals. The positive account of moral decision-making Brody offers is a pluralist, casuist, intuitionist one: the model of conflicting appeals (pp. 72-99). The model recognizes multiple, not necessarily compatible, moral appeals as legitimate and worthy of consideration. Intuitions shape how we look at cases, and looking at cases helps refine our intuitions.

4. Richardson says at the beginning of this paper, "I suppose that developing an adequate set of action-guiding principles - at least in a fast-changing context such as bioethics, if not in human life in general - requires the progressive collaboration of many practitioners and theorists, each building on the work of others" (2000, p. 286).

5. Some of the most important recent arguments for casuistic analysis in the bioethics literature include those of Strong (1997), Brody (1988), and Jonsen and Toulmin (1988).

\section{REFERENCES}

Beauchamp, T.L. (2000). 'Reply to Strong on principlism and casuistry,' The Journal of Medicine and Philosophy 25(3), 342-347.

Beauchamp, T.L. and Childress, J.F. (1979). Principles of Biomedical Ethics, Oxford University Press, New York.

Brody, B.A. (1988). Life and Death Decision Making, Oxford University Press, Oxford and New York.

Cronin, D.A. (1958). The Moral Law in Regard to the Ordinary and Extraordinary Means of Conserving Life, Rome, Typis Pontificiae Universitatis Gregorianiae.

DeGrazia, D. (1992). 'Moving forward in bioethical theory: Theories, cases, and specified principlism,' The Journal of Medicine and Philosophy 17(5), 511-539.

Engelhardt, H.T. (2000). The Foundations of Christian Bioethics, Swets and Zeitlinger, Lisse, The Netherlands.

Engelhardt, H.T. (1996). The Foundations of Bioethics, 2nd edition, Oxford University Press, Oxford and New York.

Gert, B., Culver, C., and Clouser, K.D. (2000). 'Common morality versus specified principlism: Reply to Richardson,' The Journal of Medicine and Philosophy 25(3), 308-322.

Jonsen, A.R. (1998). The Birth of Bioethics, Oxford University Press, New York and Oxford.

Jonsen, A.R. (2000). 'Strong on specification,' The Journal of Medicine and Philosophy 25(3), 348-360.

Jonsen, A.R. and Toulmin, S. (1988). The Abuse of Casuistry, University of California Press, Berkeley and Los Angeles.

Richardson, H.S. (1990). 'Specifying norms as a way to resolve concrete ethical problems,' Philosophy and Public Affairs 19, 279-310.

Richardson, H.S. (2000). 'Specifying, balancing, and interpreting bioethical principles,' The Journal of Medicine and Philosophy 25(3), 285-307.

Strong, C. (1997). Ethics in Reproductive and Perinatal Medicine: A New Framework, Yale University Press, New Haven.

Strong, C. (2000). 'Specified principlism: What is it, and does it really resolve cases better than casuistry?' The Journal of Medicine and Philosophy 25(3), 323-341.

Wulff, H. (1981). Rational Diagnosis and Treatment, 2nd ed., Blackwell Scientific, London. 